novye tendentsii sudebno-meditsinskoy avtomobil'noy travmy [Current state and new trends of forensic medical examination of car injuries]. Sudovo-medychna ekspertyza. 2017;2:7-11. (in Russian)

2. Matyshev AA. Vozmozhnosti sudebno-meditsinskoy ekspertizy pri rassledovanii avtotransportnykh proisshestviy [Forensic capabilities in the investigation of motor vehicle accidents]. Sudebno-meditsinskaya ekspertiza. 1966;3:12-5. (in Russian)

3. Plevinskis PV. Sudebno-meditsinskaya i kompleksnaya ekspertiza sovremennoy avtomobil'noy travmy [Forensic and comprehensive examination of modern car injuries]. Odessa: Astroprint; 2017. 345 s. (in Russian)

4. Solokhin AA. Sudebno-meditsinskaya ekspertiza v sluchayakh avtomobil'noy travmy [Forensic examination in cases of car injury]. Moskva: Meditsina; 1968. 235 s. (in Russian)

5. Steshits VK. Sudebno-meditsinskaya ekspertiza pri dorozhno-transportnykh proisshestviyakh [Forensic medical examination in traffic accidents]. Minsk: Belarus'; 1976. 190 s. (in Russian)

6. Derzhavna sluzhba statystyky Ukrainy. Demohrafichnyi pasport terytorii: Zhytomyrs'ka oblast' [Demographic passport of the territory - Zhytomyr region] [Internet]. Kyiv: Derzhstat Ukrainy; 2009 [onovleno 18 Ber 2017; tsytovano 26 Lys 2017]. Dostupno: http://database.ukrcensus.gov.ua/Mult/Dialog/statfile1_c_files/pasport1.htm?18\#top (in Ukrainian)

\title{
FATAL INJURIES TO PASSENGER CAR OCCUPANTS IN ZHYTOMYR REGION BETWEEN 2008 AND 2017
}

\section{Zozulia V. M.}

Summary. The current study determines the number of passenger car occupants involved in a fatal crash in Zhytomyr region between 2008 and 2017 with due regard to the adjusted risk ratio for fatal injuries to drivers and passengers. The findings also provide a rationale for the distribution of road traffic accidents in terms of the place of a road accident and the functional type of the roadway within the national roadway system.

Keywords: road traffic accident, roadway, driver, passenger.

\section{СУДЕБНО-МЕДИЦИНСКАЯ ОЦЕНКА СЛУЧАЕВ ЛЕТАЛЬНОЙ ТРАВМЫ В САЛОНЕ ЛЕГКОВЫХ АВТОМОБИЛЕЙ НА ТЕРРИТОРИИ ЖИТОМИРСКОЙ ОБЛАСТИ С 2008-2017 ГОДЫ}

\author{
Зозуля В. М.
}

\begin{abstract}
Резюме. Проведен анализ случаев дорожно-транспортных происшествий со смертельно травмированными лицами в салоне легковых автомобилей при дорожно-транспортных происшествиях на территории Житомирской области на протяжении 20082017 гг. Для установления соотношения между количеством травмированных водителей и пассажиров. Установлено распределение проишествий в зависимости от места совершения дорожно-транспортного происшествия и значением автомобильной дороги.
\end{abstract}

Ключевые слова: дорожно-транспортное происшествие, автомобильная дорога, водитель, пассажир.

DOI: https://doi.org/10.24061/2707-8728.1.2018.21

УДК 340.6:616-001: 629.1131.115

\section{СКЛОВИДНЕ ТІЛО ЯК ОБ'ЄКТ ДОСЛІДЖЕННЯ В СУДОВО- МЕДИЧНІЙ ЕКСПЕРТИЗІ}

\author{
Бачинський В.Т., Саркісова Ю.В. \\ ВДНЗ України «Буковинський державний медичний університет»
}

\begin{abstract}
Резюме. В статті представлений аналіз сучасних літературних даних щодо будови та структурних особливостей скловидного тіла ока людини, а також розглянута можливість його застосування в якості об'єкта дослідження при встановленні давності настання смерті.

Ключові слова: давність настання смерті, скловидне тіло, методи діагностики, судово-медична експертиза.
\end{abstract}

ВСТУП. Скловидне тіло (СТ) - анатомічне утворення, яке має прозорі властивості та особливу будову. Воно унікальне за своїм складом та анатомічним розташуванням, ізольоване від інших рідин організму. СТ заповнює 65\% порожнини ока, його об'єм складає $3,7-4,0 \mathrm{~cm}^{3}$. Дане анатомічне утворення є біологічною, гідрофільною, колоїдною системою, яке складається на $98-99 \%$ із води, близько $10 \%$ води знаходиться в зв'язаному стані. Решта $2 \%$ припадає на білки, полісахариди, протеоглікани, і метаболітів. СТ містить білок вітреїн та гіалуронову кисло- ту. Комплекс взаємодії 
різних типів колагену в СТ, їх особливе просторове поєднання між собою і гіалуроновою кислотою, забезпечує його прозорість, рівень в'язкості, світлозаломлювання, формують строму та регулюють процес проникнення через нього різних речовин [4].

СТ $є$ оптично прозорим позаклітинним матриксом, який покриває сітківку, війчасте тіло і кришталик. Зовні СТ обмежується пограничною мембраною - корою СТ, яка утворює нещільні з'єднання із сітківкою. Погранична мембрана поділяється на дві частини. Задня частина знаходиться ззаду зубчастої лінії, а передня - попереду від неї. Передня гіалоїдна мембрана поділяється на зонулярну і ретролентальну частини, межою між цими відділами є зв'язка Вігера, вона йде від мембрани СТ у напрямку до капсули кришталика. Задня гіалоїдна мембрана міцно спаяна з сітківкою по зубчастій лінії і по краю диска зорового нерва [6].

Власне саме СТ, розділене особливими мембранами на окремі камери - воронкоподібні комплекси (інша їх назва - вітреальні тракти). Виділяють гіалоїдний, вінцевий, серединний і преретинальний тракти. Вінцевий і серединний починаються від зонулярного відділу передньої гіалоїдної мембрани, така будова цих комплексів стабілізує передню частину склоподібного тіла при рухах всього очного яблука. Всі тракти мають вигнуту у вигляді англійської літери $\mathrm{S}$ форму [6].

Будова кортикального шару представлена гіалоцитами - особливими клітинами, які виробляють ретикулін $\mathrm{i}$ гіалуронову кислоту. Ці речовини необхідні для того, щоб структура всього СТ ока була незмінною. СТ всередині має Клокетів канал і кілька дрібніших каналів (канал Петрі, канал Ганновера, лентикомакулярний і оптико-циліарний канали), які вважаються залишками тканин артерії, яка бере участь в кровопостачанні кришталика ока в період внутрішньоутробної закладки органів [4,7].

Електролітний склад СТ включає: калій 7,7 (3,3-12,0) мекв/л, кальцій 3,6 (2,8- 5,2) мекв/л, натрій 144,0 $(118,0-154,0)$ мекв/л, фосфор $1,2(0,1-3,3)$ мекв/л, хлориди $114,0(89,0-145,0)$ мекв/л; азотовмісні сполуки (мг/100 мл): билирубин 0 - 0,001, креатинін $1,2(0,3-3,0)$, сечовина 79,0 (24,0-172); вуглеводи: глюкоза $62,0(17,0-105,0)$ мг/100мл, гексоза мін 37,0 мкг/г [6].

Деякі автори проводили мас-спектрометрію СТ [6]. За іiі результатами було виявлено велику кількість унікальних білків, серед яких у найбільшій кількості були: трансферин, альбумін, кластерин, інгібітори серпін пептидази, транстиретин, кристалін, фібрилін 1, віментин, імуноглобуліни, енолаза, С3, С4А, С4В, церулоплазмін, піруваткіназа. Кожна з підструктур СТ варіювали один від одного за складністю і можуть бути ідентифіковані, як окремі тканини на основі їх молекулярного підпису [8].

В сучасних літературних джерелах висвітлено багато наукових праць присвячених дослідженню СТ ока людини, зокрема встановленню давності настання смерті (ДНС). На нашу думку така зацікавленість СТ, як об'єктом дослідження зумовлена тим, що воно володіє сталістю хімічного складу, оточене щільними оболонками, що забезпечують його стерильність та ізольованість від інших середовищ організму, а також легко доступне для вивчення [1].

Проведено велику кількість досліджень, пов'язаних з вивченням вмісту калію в рідини СТ в залежності від ДНС. Рідина СТ досліджують за допомогою полум'яного фотометра. За даними Н.П. Марченко, кількість калію закономірно збільшується паралельно до термінів, які пройшли після смерті. Температура навколишнього середовища, на його думку, не грала ніякої ролі. Розроблена методика дозволяє встановлювати ДНС протягом перших 48-54 год після смерті. Однак на результати впливає вид смерті. Таким чином за допомогою даного ме- тоду можна визначити ДНС з точністю 3-6 год - у випадках раптової смерті, 6-12 год при механічних травмах та до 12 год при інших видах смерті (або без урахування виду і причини смерті) [3].

За даними J.M. Skeie, C.N. Roybal, V.B. Mahajan надійність вище описаного методу дослідження зменшується зі збільшенням ДНС [12]. Дослідження авторів показали, що рівень калію в СТ може варіюватися між очима однієї і тієї ж людини в один і той же час. Крім того, супутні патологічні стани та фактори, які при- скорюють розкладання, також можуть впливати на кількість калію в СТ [13,15].

I.А. Ледянкіна, використовуючи промисловий фотоколориметр, провела дослідження оптичної щільності СТ на різних етапах посмертного періоду в трьох температурних інтервалах зберігання зразка. Встановлено, що у всіх випадках у міру збільшення ДНС величина оптичної щільності достовірно підвищувалася за логарифмічним законом. При цьому статево-вікові особливості, наявність етанолу в крові та види смерті не впливають на величину оптичної щільності СТ [5].

Ще одним дослідженням СТ для встановлення ДНС було визначення його електропровідності [5]. А.М. Онянов розробив методику встановлення величини поляризації СТ перемінним струмом. Була встановлена залежність величини коефіцієнту дисперсії електропровідності СТ від ДНС. Запропонований алгоритм дозволяє встановити час смерті в часовому інтервалі з 3 по 8 добу посмертного періоду. Наявність етанолу в крові та види смерті не впливають на електричний опір СТ. Однак слід враховувати вікові особливості досліджуваного об’єкта, оскільки здатність СТ до електричної поляризації під дією перемінного струму змінюється з віком, що є загальною тенденцією старіючого організму до зміни своїх морфофункціональних характеристик [5].

Також слід відзначити наукові дослідження Ю.В. Єрмакової, які полягають у визначенні ДНС в пізньому посмертному періоді методом спінових зондів з використанням СТ. Швидкість реакції відновлення 1-оксил-4- оксо2.2.6.6.-тетраметил-піперидину залежно від ДНС можна описати рівняннм регресії. Використання даного рівняння 
дозволяє визначити ДНС з точністю 3 год з 3-ї по 10-ту добу після настання смерті [2]. При цьому необхідно враховувати наявність етанолу в крові трупа, а також температуру навколишнього середовища і відносну вологість повітря.

Ми пропонуємо розглянути СТ з оптичної точки зору. Воно являє собою багатокомпонентну рідину, до складу якої входять дві основні фракції: оптично ізотропна - оптично гомогенний комплекс гіалуронової кислоти з білками та гіалоцитами; оптично анізотропна — рідкокристалічна фаза, що складається із сукупності рідких кристалів різних типів: фібринових ниток, колагенових волокон [11,14].

Така структура надає СТ людини властивостей одновісних рідких кристалів, що дозволяє досліджувати його лазерними поляриметричними методами [9].

Виходячи із запропонованої моделі структури СТ, можна припустити, що в процесі їх зондування лазерним випромінюванням одночасно будуть формуватися оптично-ізотропні складові зображення, що відповідає координатному розподілу ізотропних складових СТ, та поляризаційно неоднорідні складові зображення, зумовлені впливами оптично анізотропних рідкокристалічних структурних елементів [10,11].

Таким чином, можна дослідити головні посмертні оптичні зміни СТ людини при різних термінах настання смерті, які пов'язані із трансформацією його оптико-анізотропної структури.

\section{ВИСНОВКИ.}

Отже, провівши поглиблений аналіз сучасних літературних джерел стосовно можливості встановлення давності настання смерті шляхом дослідження скловидного тіла ока людини можна зробити наступні висновки:

1) скловидне тіло може бути обране як об'єкт дослідження, оскільки стале за своїм хімічним складом, стерильне, оточене щільними оболонками, що тривалий час не піддаються гнилісним змінам, легко доступне для вивчення.

2) враховуючи значну оптичну активність, доцільним буде поглиблене дослідження скловидного тіла ока людини для виявлення характерних змін залежно від часу настання смерті.

\section{Література}

1. Буйнов АА. Стекловидное тело глаза человека как объект для судебно-медицинского. Материалы международной научно-практической конференции "Проблемы экспертизы в медицине". Минск; 2016. с. 38-40.

2. Ермакова ЮВ. Способ определения давности наступления смерти методом спиновых зондов. Медицинская экспертиза и право. 2012;1:32-4.

3. Марченко НП, Губин НМ. Пламенно-фотометрическое исследование жидкости стекловидного тела применительно к установлению давности смерти. Лабораторная диагностика на службе судебной медицины. 1985; 9-11.

4. Харлап СИ, Щеголева ТА, Анджелова ДВ, Фахрутдинова АФ. Морфофункциональные особенности стекловидного тела [Morphological and functional features of vitreous]. Вестник офтальмологии. 2012;3(128):48-54.

5. Онянов АМ, Ледянкина ИА, Хохлов СВ. Обоснованность выбора стекловидного тела в качестве объекта судебномедицинских исследований [Validity of choice of the vitreous body as object of medicolegal researches]. Проблемы експертизы в медицине. 2007;4:12-6.

6. Рева ГВ, Лемешко ТН, Альбрандт КФ, Можилевская ЕС, Балдаев СН, Вершинина СС и др. Развитие, строение, патология, биохимия стекловидного тела глаза человека [Development, structure, pathology and biochemistry of the vitreous body of the human eye] [Интернет]. Современные проблемы науки и образования. 2017;5 [обновлено 2017 Окт 9; цитировано 2018 Фев 3]. Доступно: https://www.science-education.ru/ru/article/view?id=26961

7. Алексеев ИБ, Белкин ВЕ, Самойленко АИ, Гулария АА. Стекловидное тело. Строение, патология и методы хирургического лечения (обзор литературы) [Vitreous. Anatomy, pathology and methods of surgical treatment (literary review)]. РМЖ. Клиническая офтальмология. 2014;4:224-7.

8. Ansari N, Lodha A, Menon SK. Smart platform for the time since death determination from vitreous humor cystine. Biosens Bioelectron. 2016;86:115-21. doi: 10.1016/j.bios.2016.06.042

9. Bachinskyi VT, Vanchuliak OY, Zozulia VM, Sarkisova YV, Garazdiuk MS, Garazdiuk OI. Diagnosing pathological conditions using laser polarimetry methods in forensic medical practice. Folia Societatis Medicinae Legalis Slovacae. 2017; 2(7):98-100.

10. Cocco L, editor. Modern Metrology Concerns. InTech; 2012. Angelsky OV, Polyanskii PV, Mokhun II, Zenkova CYu, Bogatyryova HV, Felde ChV, et al. Optical Measurements: Polarization and Coherence of Light Fields; p. 263-316.

11. Ushenko VO, Olar OV, Ushenko YuO, Gorsky MP, Soltys IV. Polarization correlometry of polycrystalline films of human liquids in problems of forensic medicine. Proc. SPIE 9809, Twelfth International Conference on Correlation Optics, 98091B [Internet]. 2015 Nov 30 [cited 2018 Feb 3]. Available from: https://www.spiedigitallibrary.org/conferenceproceedings-of-spie/9809/98091B/Polarization-correlometry-of-polycrystalline-films-of-human-liquids-inproblems/10.1117/12.2228997.short?SSO=1. doi: 10.1117/12.2228997

12. Skeie JM, Roybal CN, Mahajan VB. Proteomic insight into the molecular function of the vitreous. PloS One. 2015;10(5):e0127567. doi: 10.1371/journal.pone.0127567

13. Patel UP, Patel JB, Prajapati P, Govekar G. Study to Evaluate of Time Since Death From Potassium Level of Vitreous Humour. National Journal of Medical Research. 2016;6(3):255-8.

14. Ushenko VO, Vanchuliak OY, Sakhnovskiy MYu, Dubolazov OV, Grygoryshyn P, Soltys IV. et al. System of Mueller 
matrix polarization correlometry of biological polycrystalline layers. Proc. SPIE 10352, Biosensing and Nanomedicine X, 103520U [Internet]. 2017 Aug 29 [cited 2018 Feb 3]. Available from: https://www.spiedigitallibrary.org/conferenceproceedings-of-spie/10352/103520U/System-of-Mueller-matrix-polarization-correlometry-of-biological-polycrystallinelayers/10.1117/12.2273789.short. doi: 10.1117/12.2273789

15. Tumram NK, Bardale RV, Dongre AP. Postmortem analysis of synovial fluid and vitreous humour for determination of death interval: a comparative study. Forensic Sci Int. 2011; 204(1-3):186-90. doi: 10.1016/j.forsciint.2010.06.007

\section{References}

1. Buynov AA. Steklovidnoe telo glaza cheloveka kak ob"ekt dlya sudebno-meditsinskogo [The vitreous body of the human eye as an object for forensic medicine]. Materialy mezhdunarodnoy nauchno-prakticheskoy konferentsii "Problemy ekspertizy v meditsine". Minsk; 2016. s. 38-40. (in Russian)

2. Ermakova YuV. Sposob opredeleniya davnosti nastupleniya smerti metodom spinovykh zondov [Method for determining the prescription of death by the spin probe method]. Meditsinskaya ekspertiza i pravo. 2012;1:32-4. (in Russian)

3. Marchenko NP, Gubin NM. Plamenno-fotometricheskoe issledovanie zhidkosti steklovidnogo tela primenitel'no k ustanovleniyu davnosti smerti [Flame-photometric study of the vitreous fluid in relation to establishing the prescription of death]. Laboratornaya diagnostika na sluzhbe sudebnoy meditsiny. 1985; 9-11. (in Russian)

4. Kharlap SI, Shchegoleva TA, Andzhelova DV, Fakhrutdinova AF. Morfofunktsional'nye osobennosti steklovidnogo tela [Morphological and functional features of vitreous]. Vestnik oftal'mologii. 2012;3(128):48-54. (in Russian)

5. Onyanov AM, Ledyankina IA, Khokhlov SV. Obosnovannost' vybora steklovidnogo tela v kachestve ob"ekta sudebnomeditsinskikh issledovaniy [Validity of choice of the vitreous body as object of medicolegal researches]. Problemy ekspertizy v meditsine. 2007;4:12-6. (in Russian)

6. Reva GV, Lemeshko TN, Al'brandt KF, Mozhilevskaya ES, Baldaev SN, Vershinina SS i dr. Razvitie, stroenie, patologiya, biokhimiya steklovidnogo tela glaza cheloveka [Development, structure, pathology and biochemistry of the vitreous body of the human eye] [Internet]. Sovremennye problemy nauki i obrazovaniya. 2017;5 [onovleno 2017 Okt 9; tsitirovano 2018 Fev 3]. Dostupno: https://www.science-education.ru/ru/article/view?id=26961 (in Russian)

7. Alekseev IB, Belkin VE, Samoylenko AI, Gulariya AA. Steklovidnoe telo. Stroenie, patologiya i metody khirurgicheskogo lecheniya (obzor literatury) [Vitreous. Anatomy, pathology and methods of surgical treatment (literary review)]. RMZh. Klinicheskaya oftal'mologiya. 2014;4:224-7. (in Russian)

8. Ansari N, Lodha A, Menon SK. Smart platform for the time since death determination from vitreous humor cystine. Biosens Bioelectron. 2016;86:115-21. doi: 10.1016/j.bios.2016.06.042

9. Bachinskyi VT, Vanchuliak OY, Zozulia VM, Sarkisova YV, Garazdiuk MS, Garazdiuk OI. Diagnosing pathological conditions using laser polarimetry methods in forensic medical practice. Folia Societatis Medicinae Legalis Slovacae. 2017; 2(7):98-100.

10. Cocco L, editor. Modern Metrology Concerns. InTech; 2012. Angelsky OV, Polyanskii PV, Mokhun II, Zenkova CYu, Bogatyryova HV, Felde ChV, et al. Optical Measurements: Polarization and Coherence of Light Fields; p. 263-316.

11. Ushenko VO, Olar OV, Ushenko YuO, Gorsky MP, Soltys IV. Polarization correlometry of polycrystalline films of human liquids in problems of forensic medicine. Proc. SPIE 9809, Twelfth International Conference on Correlation Optics, 98091B [Internet]. 2015 Nov 30 [cited 2018 Feb 3]. Available from: https://www.spiedigitallibrary.org/conference-proceedings-of-spie/9809/98091B/Polarization-correlometry-ofpolycrystalline-films-of-human-liquids-in-problems/10.1117/12.2228997.short?SSO=1. doi: 10.1117/12.2228997

12. Skeie JM, Roybal CN, Mahajan VB. Proteomic insight into the molecular function of the vitreous. PloS One. 2015;10(5):e0127567. doi: 10.1371/journal.pone.0127567

13. Patel UP, Patel JB, Prajapati P, Govekar G. Study to Evaluate of Time Since Death From Potassium Level of Vitreous Humour. National Journal of Medical Research. 2016;6(3):255-8.

14. Ushenko VO, Vanchuliak OY, Sakhnovskiy MYu, Dubolazov OV, Grygoryshyn P, Soltys IV. et al. System of Mueller matrix polarization correlometry of biological polycrystalline layers. Proc. SPIE 10352, Biosensing and Nanomedicine X, 103520U [Internet]. 2017 Aug 29 [cited 2018 Feb 3]. Available from: https://www.spiedigitallibrary.org/conferenceproceedings-of-spie/10352/103520U/System-of-Mueller-matrix-polarization-correlometry-of-biological-polycrystallinelayers/10.1117/12.2273789.short. doi: 10.1117/12.2273789

15. Tumram NK, Bardale RV, Dongre AP. Postmortem analysis of synovial fluid and vitreous humour for determination of death interval: a comparative study. Forensic Sci Int. 2011; 204(1-3):186-90. doi: 10.1016/j.forsciint.2010.06.007

\section{СТЕКЛОВИДНОЕ ТЕЛО КАК ОБЪЕКТ ИССЛЕДОВАНИЯ В СУДЕБНО- МЕДИЦИНСКОЙ ЭКСПЕРТИЗЕ}

\section{Бачинский В.Т., Саркисова Ю.В.}

Резюме. В статье представлен анализ современных литературных данных о строении и структурных особенностях стекловидного тела глаза человека, а также рассмотрена возможность его применения в качестве объекта исследования при установлении давности наступления смерти. 
Ключевые слова: давность наступления смерти, стекловидное тело, методы диагностики, судебно-медицинская экспертиза.

\title{
VITREOUS BODY AS OBJECT OF RESEARCH IN FORENSIC MEDICAL EXPERTISE
}

\author{
Bachinsky V.T., Sarkisova Yu.V.
}

Summary. The article presents an analysis of modern literature on the structure and structural features of the vitreous body of the human eye, as well as the possibility of its application as an object of investigation in establishing the time since death.

Key words: time since death, vitreous body, diagnostic methods, forensic medical examination.

DOI: https://doi.org/10.24061/2707-8728.1.2018.22

УДК 616-005.1-07:340.62

\section{СУЧАСНИЙ СТАН СУДОВО-МЕДИЧНОЇ ДІАГНОСТИКИ ГОСТРИХ КРОВОВТРАТ}

\author{
Бачинський В.Т., Сивокоровська А-В.С. \\ ВДНЗ України «Буковинський державний медичний університет»
}

\begin{abstract}
Резюме. У статті наведено огляд літератури щодо існуючих методів визначення гострої крововтрати при судово-медичному дослідженні трупа, розглянуто сучасний стан проблеми та перспективи іiї вирішення.

Ключові слова: гостра крововтрата, судово-медична експертиза, лазерна поляриметрія.
\end{abstract}

Вступ. Крововтрата - є однією з причин смерті, що часто зустрічається у практиці лікаря судово-медичного експерта. Щорічно ми спостерігаємо тенденцію зростання смертельних випадків травматичного ушкодження 3 крововтратою (К). При гострій крововтраті (ГК) кров у великій кількості витікає назовні, в інших випадках накопичується у порожнинах тіла, або ж відбувається поєднання обох видів К.

ГК зі смертельним наслідком найчастіше розвивається внаслідок ушкодження магістральних судин, серця чи паренхіматозних органів. Провідна роль у патогенезі порушення функціонування організму при К належить гемодинамічним розладам по типу судинної недостатності. Недостатність кровообігу тягне за собою порушення кровопостачання органів та систем організму з подальшим розвитком кисневого голодування. Смерть настає внаслідок паралічу дихального центру. Серце зупиняється одночасно або через деякий час [1].

Для задовільного функціонування організму та внутрішніх органів велике значення має збереження в організмі сталого об'єму циркулюючої крові. В нормальних умовах у чоловіків об'єм циркулюючої крові складає 70 мл/кг, проте 3 віком зменшується до 65 мл/кг, що приблизно складає 7\% маси тіла чоловіка. У жінок ця величина складає 55-60 мл/кг (6,5\% маси тіла жінки), проте жінки менш чутливі до К ніж чоловіки [2]. При зменшенні такого об'єму, наступає централізація кровообігу - переважне кровопостачання життєво важливих органів за рахунок недостатнього кровопостачання інших.

Велика кількість крові, виявлена в порожнинах та внутрішніх органах трупа, не є визначальною для встановлення темпу К, iї кратності, а також визначення тривалості термінального процесу [3]. При пораненні м'яких тканин iз ушкодженням великих кровоносних судин зазвичай розвивається ГК, що найчастіше призводить до смерті [4]. Смерть може настати навіть при ГК у незначній кількості - об'ємом близько 500 мл. У той самий час повільна К, об'ємом 2л і більше, оцінюється як небезпечна для життя, проте може не бути летальною за рахунок розвитку компенсаторних процесів в організмі.

Провівши огляд та проаналізувавши експериментальні та експертні дослідження, що висвітлені у науковій медичній літературі, видно що деякі автори описують зміни в тканинах головного мозку, серця, легень, нирок та надниркових залоз при К, поєднаній з черепно-мозковою травмою, алкогольною чи наркотичною інтоксикаціями, а також без них $[3,5]$.

До загальних патоморфологічних проявів гострого малокрів’я відносять: наявну різко виражену блідість шкірних покривів тіла, слизових та серозних оболонок; повільне утворення трупних плям і слабкий їх прояв; різко виражене трупне заклякання; блідість, знекровлення внутрішніх органів з глинистим відтінком (печінки, нирки, серця), та суховатістю поверхні розрізу (легені); селезінка зменшена в розмірах, зморщена; мала кількість крові в судинах та порожнинах серця $[6,7]$.

Досить частою ознакою даного патологічного процесу - $\epsilon$ точкові крововиливи під ендокард лівого шлуночка серця (плями Мінакова). П.А. Мінаков вважав, що дані крововиливи виникають у результаті роботи «порожнього» 